\title{
Prosthetic Heart Valves and Pregnancy: Challenges and Solutions
}

\author{
Akshyaya Pradhan ${ }^{1} \quad$ Vikas Gupta $^{1}$ Pravesh Vishwakarma ${ }^{1}$ \\ 1Department of Cardiology, King George's Medical University, \\ Lucknow, Uttar Pradesh, India \\ Address for correspondence Akshyaya Pradhan, DM, FACC, FAPSIC, \\ FICA, Department of Cardiology, King George's Medical University, \\ Lucknow, Uttar Pradesh, India (e-mail: akshyaya33@gmail.com).
}

\begin{abstract}
With improved outcomes of valvular heart diseases and prosthetic valves, many women now survive into child-bearing age and pregnancy. However, the presence of prosthetic valves in pregnancy has an adverse impact on both maternal and fetal outcomes. The bioprosthetic or tissue valves are less thrombogenic. They do not need any anticoagulation and lead to normal pregnancy with normal baseline valve function. However, they have high rate of structural degeneration, especially in the young with an attendant need of reoperation leading to morbidity. Mechanical valves have excellent hemodynamics during pregnancy but are inherently thrombogenic leading to thromboembolic complications, necessitating uninterrupted anticoagulation. Anticoagulation itself leads to a host of maternal and fetal bleeding complication as well as adverse fetal anomalies. The use of low-dose warfarin throughout pregnancy has the best maternal safety profile. Added to this regimen, targeted replacement

Keywords

- antenatal care

- bioprosthetic valve

- embryopathy

- mechanical valve

- warfarin with parenteral heparin during the first ( $6-12$ weeks) and late third trimesters (beyond 36 weeks) leads to virtual elimination of embryopathy as well as appreciable reductions of maternal mortality. Proper preconception counseling and antenatal care coupled with planned labor or delivery is essential to ensure best outcomes. These patients are best managed in a tertiary care center with proper expertise in managing adverse cardiovascular, obstetric, and neonatal outcomes.
\end{abstract}

\section{Introduction}

Prosthetic heart valves pose unique challenges in pregnancy with increased maternal and fetal morbidity. The choice of prosthetic valve in pregnancy is a difficult one. On the one hand are the mechanical valves with excellent hemodynamic parameters during pregnancy, but the need for seamless anticoagulation increases risk for both the mother and fetus. On the other hand are bioprosthetic valves that obviate the need for anticoagulation but compromise on the valve durability and there is also an increased risk of prosthetic valve dysfunction. In this review, we briefly discuss the risks associated with prosthetic valve in pregnancy, the determinants and salient features of management in a pregnant woman with prosthetic valve in situ.

\section{Pregnancy and Altered Cardiovascular Hemodynamics}

Physiologic adaptations are seen in pregnancy to optimize fetal growth and development. The major cardiovascular hemodynamic changes seen in pregnancy include increased cardiac output, expanded blood volume, and reduced systemic vascular resistance and blood pressure. Increased preload (due to the expansion of the blood volume), decreased afterload (due to the decreased systemic vascular resistance), and increased maternal heart rate all lead to increased cardiac output and workload. ${ }^{1,2}$ Pregnancy is also considered as a hypercoagulable state. Changes in several clotting factors are seen in pregnancy: 
1. Increase in procoagulants

a. Increase in factors I, II, V, VII, VIII, X, and XII

b. Increased platelet adhesiveness

c. Increased activity of plasminogen activator inhibitors

2. Decrease in anticoagulants

a. Decrease in free protein $\mathrm{S}$

b. Increase in activated protein $\mathrm{C}$ resistance

This hypercoagulable state of the pregnancy is an adaptive feature of the pregnancy to decrease blood loss. However, on the other hand, it increases risk of thromboembolic complications in patients with prosthetic valves, which can be catastrophic for both the mother and child. ${ }^{2}$ Various types of arrhythmia are also seen in pregnancy with increased frequency. The exact mechanism of this is unknown, but various hemodynamic, hormonal, and autonomic changes related to pregnancy are considered as probable mechanisms.

\section{Risk Stratification with Prosthetic Valves}

Risk of cardiovascular complications in pregnancy depends on three factors: disease-specific factors, general pregnancy-related factors, and patient-related specific variables. Maternal and neonatal health conditions are interrelated. In most studies, risk factors for both maternal and neonatal cardiovascular events have been studied.

\section{Risk Prediction Scores-ZAHARA, WHO, and CARPREG}

Commonly used risk scores to predict complications during pregnancy in women with cardiac disease are the Cardiac Disease in Pregnancy (CARPREG), Zwangerschap bij Aangeboren Hartafwijkingen (ZAHARA) risk scores, and World Health Organization (WHO) maternal risk classification (recommended in 2018 European Society of Cardiology [ESC] guidelines). ${ }^{3-6}$ Prosthetic valves are not included for risk stratification in CAPREG score whereas they are included as a predictor of maternal cardiovascular events in ZAHARA system. The modified WHO maternal cardiovascular risk classifies bioprosthetic valve as class II-III risk (maternal cardiac event rate of 10-19\%) whereas mechanical valves are placed in class III risk (maternal cardiac event rate of $19-27 \%)^{7,8}$

Apart from the presence of prosthetic valves, other cardiac modifiers of maternal cardiovascular outcomes include low left ventricular ejection fraction (LVEF) (<40\%), presence of pulmonary artery hypertension, left-sided obstructive lesions (moderate to severe), reduced subpulmonary ventricular function (tricuspid annular plane systolic excursion [TAPSE] $<16 \mathrm{~mm}$ ), atrioventricular valve regurgitation, and cyanotic heart disease. Clinical features predictive of worse maternal outcomes include presence of cyanosis, elevated NT-proBNP, history of prior cardiac events, use of cardiac medications, New York Heart Association (NYHA) class III/IV, and smoking. Many of these factors such as NYHA class III/IV, left heart obstruction, and smoking also predict worse fetal neonatal outcomes (-Tables 1, 2).
Table 1 Predictors of maternal cardiovascular events with commonly used risk scores in pregnancy

\begin{tabular}{|c|c|c|}
\hline CARPREG & ZAHARA & ESC 2018 \\
\hline $\begin{array}{l}\text { Prior cardiac } \\
\text { events or } \\
\text { arrhythmia }\end{array}$ & $\begin{array}{l}\text { Presence of } \\
\text { cyanotic heart } \\
\text { disease }\end{array}$ & $\begin{array}{l}\text { Prior cardiac event } \\
\text { (heart failure, } \\
\text { transient ischemic } \\
\text { attack, stroke, } \\
\text { arrhythmia) }\end{array}$ \\
\hline $\begin{array}{l}\text { Poor functional } \\
\text { class or cyanosis }\end{array}$ & $\begin{array}{l}\text { Use of cardiac } \\
\text { medication be- } \\
\text { fore pregnancy }\end{array}$ & NYHA class III/IV \\
\hline $\begin{array}{l}\text { Left heart } \\
\text { obstruction }\end{array}$ & $\begin{array}{l}\text { Left heart } \\
\text { obstruction }\end{array}$ & $\begin{array}{l}\text { Left heart obstruc- } \\
\text { tion (moderate to } \\
\text { severe) }\end{array}$ \\
\hline \multirow[t]{9}{*}{$\begin{array}{l}\text { Left ventric- } \\
\text { ular systolic } \\
\text { dysfunction }\end{array}$} & $\begin{array}{l}\text { Mechanical valve } \\
\text { replacement }\end{array}$ & $\begin{array}{l}\text { Reduced systemic } \\
\text { ventricular systolic } \\
\text { function (ejection } \\
\text { fraction }<40 \% \text { ) }\end{array}$ \\
\hline & \multirow{8}{*}{$\begin{array}{l}\text { Systemic or } \\
\text { pulmonary atrio- } \\
\text { ventricular valve } \\
\text { regurgitation } \\
\text { related with the } \\
\text { underlying (mod- } \\
\text { erately) complex } \\
\text { congenital heart } \\
\text { diseases }\end{array}$} & $\begin{array}{l}\text { Systemic atrioven- } \\
\text { tricular valve regur- } \\
\text { gitation (moderate } \\
\text { to severe) }\end{array}$ \\
\hline & & $\begin{array}{l}\text { Reduced sub- } \\
\text { pulmonary } \\
\text { ventricular function } \\
\text { (TAPSE }<16 \mathrm{~mm} \text { ) }\end{array}$ \\
\hline & & $\begin{array}{l}\text { Pulmonary } \\
\text { atrioventricular } \\
\text { valve regurgitation } \\
\text { (moderate to } \\
\text { severe) }\end{array}$ \\
\hline & & $\begin{array}{l}\text { Pulmonary arterial } \\
\text { hypertension }\end{array}$ \\
\hline & & Mechanical valves \\
\hline & & Smoking \\
\hline & & Cyanosis \\
\hline & & $\begin{array}{l}\text { Elevated } \\
\text { NT-proBNP }\end{array}$ \\
\hline
\end{tabular}

Abbreviations: CARPREG, Cardiac Disease in Pregnancy; ESC, European Society of Cardiology; NYHA, New York Heart Association; TAPSE, tricuspid annular plane systolic excursion; ZAHARA, Zwangerschap bij Aangeboren Hartafwijkingen.

In the ROPAC (Registry of Pregnancy and Cardiac Disease) registry, $58 \%$ of women with mechanical heart valves had adverse event-free pregnancy compared with $79 \%$ with tissue valves. ${ }^{9}$ The odd of having complications during pregnancy were significantly higher with mechanical valve vis-a-vis tissue valves.

\section{Maternal Risk versus Fetal Risk}

The spectrum maternal complications include miscarriage, thromboembolic complications, obstetric hemorrhage, and most severe maternal mortality. ${ }^{10}$ Cardiac complications include heart failure, arrhythmia, prosthetic valve thrombosis (PVT), and infective endocarditis (IE). Use of anticoagulation additionally predisposes to peripartum bleeding, thrombocytopenia, and osteoporosis. 
Table 2 Predictors of neonatal complications with commonly used risk scores in pregnancy

\begin{tabular}{|c|c|c|}
\hline CARPREG & ZAHARA & ESC 2018 \\
\hline Anticoagulation & $\begin{array}{l}\text { Cyanotic heart } \\
\text { disease (repaired } \\
\text { or unrepaired) }\end{array}$ & $\begin{array}{l}\text { Cyanosis during } \\
\text { baseline prenatal } \\
\text { visit } \\
\text { Low maternal } \\
\text { oxygen saturation } \\
(<90 \%)\end{array}$ \\
\hline $\begin{array}{l}\text { Poor functional } \\
\text { class or cyanosis }\end{array}$ & $\begin{array}{l}\text { The use of cardiac } \\
\text { medication } \\
\text { before pregnancy }\end{array}$ & NYHA class III/IV \\
\hline $\begin{array}{l}\text { Left heart } \\
\text { obstruction }\end{array}$ & Maternal smoking & $\begin{array}{l}\text { Maternal left heart } \\
\text { obstruction }\end{array}$ \\
\hline $\begin{array}{l}\text { Multiple } \\
\text { gestations }\end{array}$ & $\begin{array}{l}\text { Mechanical valve } \\
\text { replacement }\end{array}$ & $\begin{array}{l}\text { Smoking during } \\
\text { pregnancy }\end{array}$ \\
\hline \multirow[t]{8}{*}{ Smoking } & \multirow{8}{*}{$\begin{array}{l}\text { Multiple } \\
\text { gestations }\end{array}$} & Multiple gestations \\
\hline & & $\begin{array}{l}\text { Use of anticoagu- } \\
\text { lants throughout } \\
\text { pregnancy }\end{array}$ \\
\hline & & $\begin{array}{l}\text { Cardiac med- } \\
\text { ication before } \\
\text { pregnancy }\end{array}$ \\
\hline & & $\begin{array}{l}\text { Mechanical valve } \\
\text { prosthesis }\end{array}$ \\
\hline & & $\begin{array}{l}\text { "At birth" cyanotic } \\
\text { heart disease }\end{array}$ \\
\hline & & $\begin{array}{l}\text { Maternal cardiac } \\
\text { event during } \\
\text { pregnancy }\end{array}$ \\
\hline & & $\begin{array}{l}\text { Maternal decline } \\
\text { in cardiac output } \\
\text { during pregnancy }\end{array}$ \\
\hline & & $\begin{array}{l}\text { Abnormal utero- } \\
\text { placental Doppler } \\
\text { flow }\end{array}$ \\
\hline
\end{tabular}

Abbreviations: CARPREG, Cardiac Disease in Pregnancy; ESC, European Society of Cardiology; NYHA, New York Heart Association; ZAHARA, Zwangerschap bij Aangeboren Hartafwijkingen.

The fetus or neonate is also at risk for a host of complications, including intrauterine growth retardation, preterm birth, perinatal mortality, and small for gestational age. Anticoagulation exposure via the placenta leads to specific complications in the fetus referred commonly as "embryopathy" (when occurring due to exposure between 6 and 10 weeks and "fetopathy" due to exposure in the late gestation period). ${ }^{11}$ Vitamin $\mathrm{K}$ antagonists (VKAs) are notorious for both whereas unfractionated heparin (UFH) can cause fetopathy while used as the sole agent throughout. Low-molecular-weight heparins (LMWHs) have the lowest rate of adverse fetal outcomes as anticoagulants.

\section{Bioprosthetic Valves versus Mechanical Valves}

Bioprosthetic Valves and Pregnancy

Bioprosthetic valves (homografts, heterografts, or autografts) are much less thrombogenic than mechanical valves. ${ }^{12,13}$ However, there still remains a risk of valve thrombosis. Egbe and colleagues estimated the incidence of bio PVT as $1.5 \%$ based on data of 3,161 patients with an implanted bioprosthetic valve who underwent follow-up echocardiography at their institution over 6 years. ${ }^{14}$ The incidence may have been underestimated as only the patients who underwent surgical exploration of PVT were included whereas others who were medically managed were excluded.

However, they do obviate the need of long-term anticoagulation, thereby resulting in better maternal and fetal outcomes, as seen in ROPAC registry. Women with well-functioning bioprosthetic heart valves and those who do not have other cardiac risk factors often have uncomplicated pregnancies. However, there remains a substantial risk of structural deterioration in bioprosthetic valves in young women. ${ }^{12}$ Structural valve deterioration (SVD) occurs relatively early and rapidly in young patients. Jamieson et al found that proportion of patients free of SVD after 10 years of operation was highly dependent on age, and values in patients younger than 30 years, between 30 and 59 years, and older than 60 years were $27 \%, 77 \%$, and $84 \%$, respectively. ${ }^{15}$ The mitral valve tends to be more vulnerable than the aortic valve for structural deterioration although no such predilection was found by Egbe et al for valve thrombosis. ${ }^{13}$ Flameng et al found that lack of antimineralization treatment of valves and patient-prosthesis mismatch are the major determinants of structural valve degeneration with bioprosthetic heart valves. ${ }^{16}$ There is an controversy about acceleration of structural valve degeneration by pregnancy. Few authors support this hypothesis whereas others are against it. ${ }^{13,17}$ However, there is general agreement that degeneration occurs early in young age. ${ }^{16}$ As the risk of SVD in young women is high, this may be seen in women during pregnancy or during postpartum period. There is a significant risk of complications in patient with dysfunctional bioprosthetic valve. Dysfunctional valve may require reoperation.

Cardiovascular morbidity and mortality in pregnant women with bioprosthetic valve was studied in the ROPAC study. In the ROPAC study, maternal mortality was $1.5 \%$. In this study, heart failure was reported in $8.2 \%$ of pregnant women, endocarditis and thrombotic complications in $0.7 \%$, and hemorrhagic complications in $5.1 \%$ of pregnant patients with bioprosthetic valves. ${ }^{9}$

ROSS procedure (pulmonary autograft for aortic valve disease and placing a homograft for pulmonary valve) is a complex procedure. Although technically demanding, there is no risk of valve thrombosis and hemodynamic results are good. Homografts have the same rate of SVD as heterografts; data are not available for pregnant women with long-term follow-up. Grunkemeier et al showed 0 to $10 \%$ reoperation rate within 6 months and 0.4 to 1.5\% late reoperation rate after Ross procedure. ${ }^{18}$ Transcatheter aortic valves are not currently indicated for young patients.

\section{Mechanical Valves in Pregnancy}

Mechanical valves have excellent durability and hemodynamic profile. Mechanical prosthetic valves, however, are thrombogenic and require lifelong anticoagulation to prevent thromboembolic complications. 
Pregnancy in a woman with a mechanical heart valve is associated with high maternal and fetal complications. In women with mechanical valves, pregnancy is associated with a very high risk of complications (modified WHO risk classification III). ${ }^{8}$ In the ROPAC registry, there were 212 patients with mechanical valve. Maternal mortality was $1.4 \%$ in this registry. Hemorrhagic complications were noted in 23\% patients whereas thrombotic complications occurred in $6.1 \%$, valve thrombosis was seen in $4.7 \%$, and miscarriage in $15.6 \%{ }^{9}$ About $7.5 \%$ of pregnancies were complicated by heart failure whereas supraventricular and ventricular arrhythmias occurred in $2.8 \%$ and $0.5 \%$ of pregnancies, respectively. Postpartum hemorrhage directly after delivery and up to 24 hours postpartum occurred in $10.4 \%$.

Recently in a population-based study in the United Kingdom, Vause et al studied pregnancy outcomes in women with mechanical prosthetic valves. They studied data of 58 pregnant women with mechanical valves (incidence $3.7 / 100,000$ maternities). Only $28 \%$ women had a good maternal and fetal outcome. Poor fetal outcome was noted in $47 \%$ women. In this cohort, they observed $9 \%$ maternal mortality and $41 \%$ serious maternal morbidity. LMWH was used throughout pregnancy by $71 \%$ women in this study (the ROPAC registry mainly used warfarin, either throughout or during the second and third trimesters). Hemorrhagic complications occurred in $29 \%$ women. ${ }^{19}$

The choice of anticoagulation dictates maternal and fetal risk in mechanical valves during pregnancy. Maternal mortality estimates range between $1 \%$ and $15 \%$, depending on the series and anticoagulation strategy. ${ }^{20,21}$ Heparins (LMWH or UFH) are associated with relatively high risk of valve thrombosis. ${ }^{22,23}$ ESC 2018 guideline says that the use of VKAs throughout pregnancy, under strict international normalized ratio (INR) control, is the safest regimen to prevent valve thrombosis. LMWH is possibly superior to UFH for preventing valve thrombosis. ${ }^{8}$

"Warfarin embryopathy" is a known complication of warfarin therapy during pregnancy, mainly between the 6 th and 12th weeks of pregnancy. It is characterized by nasal hypoplasia, low birth weight, slower growth, mental retardation, malformed bones, cartilage and joints, stippled epiphyses, deafness, and small head size. ${ }^{24,25}$ Between 6 and 12 weeks of gestation, bone and cartilage formation in the fetus may be impaired by transplacental passage of warfarin, resulting in the warfarin embryopathy. The teratogenicity of warfarin is found to be somewhat dose dependent, with more frequent and more serious fetal malformations occurring when warfarin doses of greater than $5 \mathrm{mg}$ /day are given. UFH use in the last 2 weeks of pregnancy may be used to decrease the risk of peripartum hemorrhage and bleeding complications in the newborn. Elective cesarean section in the 38th week of pregnancy has also been suggested to reduce the risk of hemorrhage. A systematic review of the literature published in 2000 showed that use of heparin alone or early first-trimester conversion ( $\leq 6$ weeks) from warfarin to heparin entirely prevented the incidence of congenital anomalies. The guidance to choose either type of prosthetic valve in pregnancy is presented in - Fig. 1.
Mechanical valve

- Good long-term durability of valve

- Low rates of reoperation

- Risk of PVT \& need for anticoagulation

- Bleeding, warfarin embryopathy due to anticoagulation

- $58 \%$ chance of event free pregnancy

\section{Bioprosthetic valve}

- Anticoagulation not needed

- High rates of valve degeneration (50\% at 10 years)

- Need for reoperation increases mortality

- $79 \%$ chance of event free survival

Fig. 1 Benefits and risk of type of prosthetic valves over each other. PVT, prosthetic valve thrombosis. 


\section{Anticoagulants in Pregnancy}

Mechanical prosthetic valves need lifelong anticoagulation, and guidelines recommend target INRs to be maintained based of the type and anatomical position. Anticoagulation becomes of paramount importance in pregnant patients as it is a state of heightened risk of thrombosis. Multiple mechanisms may contribute to the elevated risk of thrombosis including elevated clotting factors, increased platelet activity, decreased fibrinolysis, and resistance to naturally occurring anticoagulants. ${ }^{26}$ In the ROPAC registry, the rates of thromboembolic complication were seen in $6.1 \%$ of pregnancies. ${ }^{9}$ Bioprosthetic valves have an edge over prosthetic valves as they do not require lifelong anticoagulation. While anticoagulation is deemed necessary from the preceding arguments, it also predisposes the mother to multitude of complications such as postpartum hemorrhage, fetal loss, preterm delivery, and low birth weight. In addition, some anticoagulants can cross the placenta and lead to teratogenicity in the fetus if administered during embryogenesis. Three types of anticoagulant regimen are used in pregnancy with mechanical heart valves: warfarin throughout, LMWH/UFH throughout, LMWH/UFH in the first trimester then warfarin until the mid-late trimester then switching back again to heparin (LMWH or UFH). The role of various currently available anticoagulants is discussed as follows.

\section{Vitamin K Antagonists}

Oral VKAs warfarin and acenocoumarol together form the mainstay of oral anticoagulation in patients with mechanical heart valves. The recommended target INRs in pregnancy is between 2.5 and 3.5, and it should be monitored on a fortnightly basis, if not on a weekly basis whenever feasible. Even in pregnancy, they have lowest maternal mortality (0.9-1.9\%) and thromboembolic episodes (2-3.9\%). ${ }^{11,20,21}$ However, by virtue of their ability to cross the placental barrier, they lead to anomalies in the fetus commonly referred to as "warfarin embryopathy" (-Table 3). ${ }^{24,25}$ The incidence varies in the literature with previous studies reporting a high incidence of around 6.4 to $7.4 \%$ whereas the recent studies peg the incidence at 2 to $3.7 \% .^{11,20,21,24}$ In addition to embryopathy, they can

Table 3 Adverse effects on warfarin or other vitamin $\mathrm{K}$ antagonists on fetus

\begin{tabular}{|l|}
\hline "Warfarin embryopathy"-3.7-6.4\% overall incidence \\
\hline $\begin{array}{l}\text { Exposure during 6-12 wk of gestation-nasal hypoplasia, } \\
\text { stippled epiphyses, mental retardation }\end{array}$ \\
\hline $\begin{array}{l}\text { Later exposure in gestation (fetopathy)-neurologic and eye } \\
\text { defects and intracranial hemorrhage during delivery }\end{array}$ \\
\hline $\begin{array}{l}\text { Fetal death from exposure at any age (33\% all-cause fetal } \\
\text { death) }\end{array}$ \\
\hline Prematurity (7.5\%) and spontaneous abortions ( $23 \%)$ \\
\hline $\begin{array}{l}\text { Lower incidence of fetal adverse events at doses }<5 \mathrm{mg} / \\
\text { day (2.3\% vs. } 12 \%)\end{array}$ \\
\hline Higher rate of live births at doses < $5 \mathrm{mg} /$ day ( $84 \%$ vs. 44\%) \\
\hline
\end{tabular}

cause prematurity (7.5\%), spontaneous abortions (23\%), and fetal wastage due to any cause (33\%). Because of high risk of fetal intracranial hemorrhage, vaginal delivery is contraindicated when mother is on VKAs.

Two strategies have been used to mitigate the risk of fetal damage with VKAs: dose alteration and replacing with heparins in the first trimester. Various studies have found that the teratogenic effects are dose dependent. The seminal studies by Vitale et al and Cotrufo et al done almost two decades ago first demonstrated the dose dependency of teratogenic effect of VKAs and found that a 5-mg dose is the ceiling beyond which adverse outcomes are prevalent. ${ }^{27,28}$ The recent meta-analysis by D'Souza et al also affirmed the same and showed that the fetus-related adverse events were drastically reduced in less than $5 \mathrm{mg}$ group at $2.3 \%$ versus the higher dose group at $12.4 \% .{ }^{11}$ On the contrary, the ROPAC registry failed to establish the dose dependency of adverse effects with VKAs. Another prudent strategy of using heparins (which do not cross the placental barrier) during the first trimester (preferably 6-13 weeks) and VKAs during the rest of pregnancy has also shown to alleviate the fetal risk. This strategy avoids the detrimental effects of warfarin on embryogenesis and has been shown to virtually eliminate the fetal embryopathy risk $(0.4 \%$ vs. $3.7 \%) .{ }^{21}$ The rates of spontaneous abortions and fetal death due to any cause were also lower with this regimen.

The thrombogenicity of newer-generation bileaflet valves (Carbomedics, Medtronic-Hall, St. Jude, and ATS) is lower than that of previously used ball-cage and tilting disc valves. The recent guidelines advocate a lower target INR of 2.5 versus 3.5 in older-generation valves (Star-Edwards, Bjork-Shiley, and Omniscience). ${ }^{7.29}$ Absence of other potential high-risk features such as mitral or tricuspid position, previous thromboembolism, concomitant atrial fibrillation (AF), LVEF less than $35 \%$, and mitral stenosis also allows for a moderation in target INR. These considerations will apply while selecting the anticoagulation regimen and the type of mechanical valve as a lower INR will ultimately reflect in potentially lower warfarin doses with fewer complications. The message on the board is clear to use the lowest possible warfarin dose in pregnancy and replacing it with heparins during 6 to 13 weeks.

\section{Heparins}

Heparins (UFH and LMWH) do not cross the placenta and appear promising as they eliminate the risk of embryopathy or fetopathy seen with VKAs. However, their use in pregnancy for thromboprophylaxis is fraught with many challenges such as lesser efficacy, poor compliance, difficulty in monitoring activated partial thromboplastin time (aPTT), thrombocytopenia, osteoporosis, and parenteral administration of drug.

\section{Unfractionated Heparin}

The use of UFH is associated with four times increased risk of thromboembolism as compared with warfarin. ${ }^{24}$ The thromboembolic complication rates and maternal mortality were high at $33 \%$ and $15 \%$, respectively. ${ }^{20}$ However, the recent literature suggests that the rate have may come down to $11.2-13 \%$ 
and $3.4-5 \%$, respectively. ${ }^{11,21}$ The promising results can be attributed to use of less thrombogenic valves and proper heparin dosing in the recent studies. ${ }^{21}$ Nevertheless, owing to high thrombotic complications, their use as standalone therapy is not recommended by guidelines., ${ }^{70}$ However, as a combination therapy with VKAs, they have high safety risk profile and are popular. The dosing should be targeted to aPTT more than two times of normal, and after attaining target aPTT only weekly monitoring is advised.

\section{Low-Molecular-Weight Heparins}

Low-molecular-weight heparins represent more feasible alternative to UFH with advantages of predictable pharmacokinetics, twice-daily dosing, subcutaneous administration, and obviating the need for aPTT monitoring. Although they represent a significant advance over heparin outside the pregnancy setting, their use in pregnancy has high thromboembolic risk (8.7\%) and maternal mortality $(2.9 \%) .{ }^{11}$ Because of increased renal clearance, the dose of LMWH is needs to be adjusted to monitored plasma anti-Xa levels. ${ }^{31}$ Although suboptimal levels and poor compliance are contributors to valve thrombosis, some reports also emerged of valve thrombosis with adequate level of anti-Xa. ${ }^{32}$ The recommended dose of enoxaparin is $1 \mathrm{mg} / \mathrm{kg}$ twice daily, and peak anti-Xa level (4-6 hours post dose) is to be kept at 0.8 to $1.2 \mathrm{IU} / \mathrm{mL}$ whereas trough levels at greater than $0.6 \mathrm{IU} /$ $\mathrm{mL}$. The corresponding dose of dalteparin is $100 \mathrm{U} / \mathrm{kg}$. Dosing should be altered daily until peak levels are attained and then checked weekly. ${ }^{33}$

\section{Novel Oral Anticoagulants}

The novel oral anticoagulants are not indicated in pregnancy as well as with prosthetic valves.

\section{Low-Dose Aspirin}

Aspirin in low doses of 75 to $100 \mathrm{mg}$, when added to VKAs, leads to decrease in major embolism, death, stroke, and mortality in patients with prosthetic valve although at the risk of increased bleeding. ${ }^{34}$ Based on these premises, the ACC/AHA (American College of Cardiology/American Heart Association) guidelines recommend continuing the low-dose aspirin therapy during pregnancy. ESC guidelines take a conservative stance and recommend against use of routine use of low-dose aspirin even in a nonpregnant setting.

\section{Simplified Anticoagulant Regimen}

The advantages and disadvantages of each anticoagulant should be discussed with the patient and family members. The primary determinant in planning of the regimen is the dose of warfarin (or acenocoumarol) required to maintain the INR in therapeutic levels. The core principle remains that VKAs are the most potent regimen to decrease thromboembolic events in the mother.

\section{Low-Dose Group-Warfarin $<5$ mg/day \\ (or acenocoumarol $<2 \mathrm{mg} /$ day)}

Because of the low risk of fetal damage in this group, continuing warfarin throughout pregnancy is the safest option. VKAs should be continued until 36 weeks. Because of high risk of maternal and fetal bleeding in anticoagulated women, she should be changed to intravenous UFH or twice-daily LMWH based on local resources and cost about 2 weeks prior to anticipated delivery. Parenteral heparin should be stopped 4 to 6 hours prior to labor and started 4 to 6 hours after delivery or when bleeding has stopped.

If a woman desires so, she can also switch to parenteral anticoagulation with heparin form 6 to 12 weeks. Interestingly, in the ROPAC registry up to $50 \%$ of valve thrombosis occurred during switching from VKA, and switching should ideally performed in hospitalized setting. ${ }^{9}$

\section{High-Dose Group-Warfarin $>5 \mathrm{mg} /$ day \\ (or acenocoumarol $>2 \mathrm{mg} /$ day)}

Because of high risk of embryopathy at such high doses, it is ideal to switch to intravenous UFH or twice-daily LMWH from 6 to 12 weeks of gestation and continue with oral VKAs for rest of pregnancy. As discussed previously, this regimen virtually has eliminated the risk of warfarin embryopathy. The choice between the two parenteral regimens would depend on cost, availability of anti-Xa assay, and facility of hospitalization. In absence of an anti-Xa assay, the guidelines advocate against use of LMWH that would be the case in many parts of our country. On the other hand, the ability to administer LMWH in an outpatient basis appears appealing and can help reduce cost of hospitalization in an already overburdened health system. Remaining part of the management remains the same as in case of low-dose group. INR monitoring on VKA is recommended on a fortnightly basis. An algorithm for anticoagulation in pregnancy with mechanical valves is presented in - Fig. 2.

\section{General Principles of Management of Pregnancy}

\section{Prepartum Counseling}

Women of child-bearing age group with prosthetic valves should have preconception counseling about the maternal cardiac and obstetric risks with pregnancy. Additionally, fetal and neonatal risks also need to be detailed. The option of avoiding pregnancy should also be clearly discussed. Baseline documentation of symptoms and echocardiographic parameters of prosthetic valve serves as a guide should the woman become pregnant.

\section{Antepartum Phase}

Prosthetic valves constitute a high-risk pregnancy and should be managed at experienced centers by team comprising the cardiologist, obstetrician (preferably with expertise in handling high-risk pregnancies), and fetal medicine expert. At the first antenatal visit, it is imperative to perform a full physical examination, electrocardiogram, and two-dimensional (2D) echocardiogram to assess valve hemodynamics. Detailed assessment of medical therapy is essential to discontinue drugs that are contraindicated in pregnancy such as angiotensin-converting enzyme (ACE) inhibitors, angiotensin receptor blockers (ARBs), and aldosterone antagonists. Discussion regarding various options for anticoagulation also is vital in women with a mechanical valve. The type of mechanical valve and 


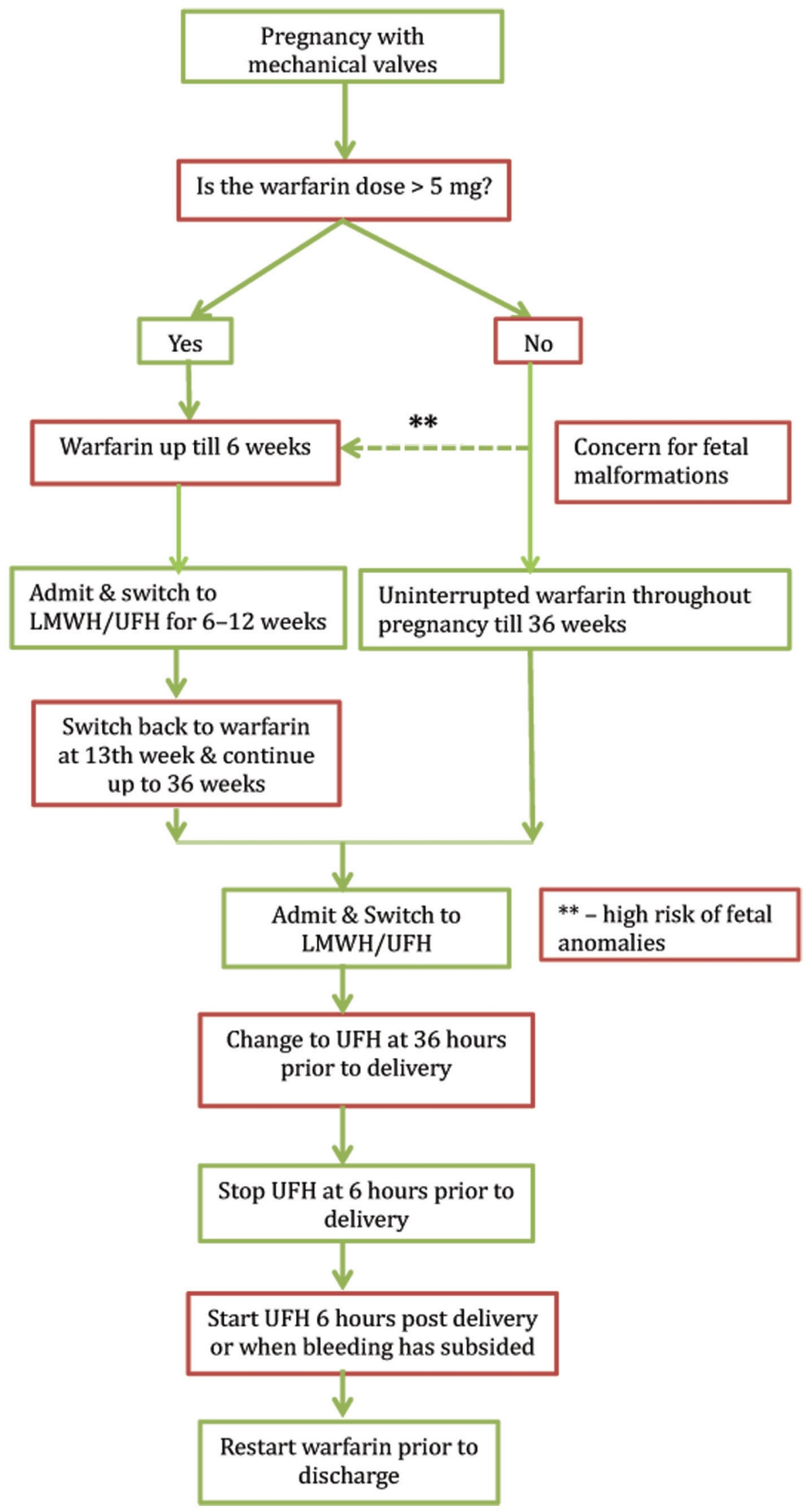

Fig. 2 Proposed algorithm for anticoagulation during pregnancy. *Equivalent doses of acenocoumarol-2 mg/day and phenprocoumon $3 \mathrm{mg} /$ day; LMWH, low-molecular-weight heparin; UFH, unfractionated heparin]. 
baseline valve functions determine the follow-up intervals. Bioprosthetic valves with good functioning can be monitored at ease in each trimester. Those with poor baseline valve function need to be monitored more frequently. For mechanical valves, need frequent monitoring for adequate anticoagulation fortnightly or preferably weekly is essential. Monthly echocardiogram and clinical follow-up are also recommended by guidelines. Any deterioration in clinical status warrants urgent attention of physician, and high index of suspicion is required for early detection of complications.

\section{Management of Delivery}

Having a predefined protocol for managing for labor and delivery leads to better maternal and fetal outcomes. For women with bioprosthetic valves, vaginal delivery is preferred. For those with a mechanical heart valve, management of anticoagulation in peripartum period is of paramount importance. Because of high risk of fetal intracranial hemorrhage, vaginal delivery on VKAs needs to be avoided. Such women need to be electively hospitalized at 36 or 2 weeks prior to scheduled delivery for switching to parenteral heparins (UFH or LMWH). For patients on LMWH, it needs to be discontinued and UFH must be started 36 hours prior to delivery and continued up to 4 to 6 hours prior to it. Its emergency delivery is required in the woman on LMWH or UFH. Protamine can be used to reverse the effects of UFH and LMWH (partial reversal possible). Elective cesarean section can also be considered in women on VKAs to minimize the interruption in anticoagulation.

For women on VKAs who present in active or preterm labor, cesarean section is the only choice. Fresh frozen plasma needs to be administered, supplemented by oral vitamin, prior to surgery to attain INR less than 2. Because of placental travel, the fetus also becomes anticoagulated and needs fresh frozen plasma and vitamin $\mathrm{K}$.

\section{Postpartum Phase}

All the anticoagulants can be safely prescribed during breast-feeding. Minimizing the interruption of VKAs is essential in patients with mechanical valves, and switch from parenteral heparin to VKAs should be done as soon as feasible. Diuretics (except spironolactone), $\beta$-blockers (preferably, metoprolol), and digoxin can be safely administered. Renin-angiotensin-aldosterone system (RAAS) (ACE inhibitors and ARBs) blockers are secreted in breast milk and are best avoided. When absolutely unavoidable, captopril, benazepril, and enalapril are advocated by the recent ESC guideline. ${ }^{8}$

\section{Contraception}

Because of the heightened risk of thrombosis in pregnancy, choice of contraception needs to be addressed carefully. Estrogen-containing pills have a risk of arterial and venous thrombosis and are best avoided. The other options to be considered are barriers methods and progesterone-based contraceptives. Failures rates are high with barrier methods and progesterone-based contraceptives like pills, intrauterine devices, etc. need to be considered in whom pregnancy will be extremely high risk (e.g., patients with double mechanical valves, prior history of PVT, prosthetic valve dysfunction). Apt consideration needs to be given to permanent contraception in patients with already completed family. The general principles of management are summarized in - Fig. 3 .

\section{Management of Complications}

\section{Prosthetic Valve Thrombosis}

High index of suspicion is required for diagnosis of PVT. Worsening of dyspnea, thrombotic events, and arrhythmias should alert the physician. Combination of clinical assessment, transthoracic and transesophageal echocardiography, and rarely, fluoroscopy should clinch the diagnosis. Management options are similar to the nonpregnant setting and include parenteral anticoagulation, fibrinolysis, and surgery. The patient's clinical status, anatomical position, and size of thrombus guide the selection of management strategy. Parenteral anticoagulation (UFH or LMWH) is ideal for the patient who is hemodynamically stable and gives past history of inadequate or interrupted anticoagulation. Fibrinolysis should be reserved for right-sided endocarditis, critically ill left-sided endocarditis with high risk for surgery or nonavailability of surgery, and finally in noncritical patients when parenteral heparin has failed. Generally, fibrinolytic agents do not cross the placenta because of their high molecular weight, but there remains a risk of placental abruption and embolization to fetus. Low-dose and slow-infusion thrombolysis with alteplase has been demonstrated to be safe and effective in PVT in pregnancy. ${ }^{35}$

Emergency surgery is required when the patient is hemodynamically unstable with obstructive thrombus and when medical therapy fails in noncritically ill patients. However, the limitations of surgery include problem of availability in odd hours and high rate of fetal (30\%) as well as maternal loss (6\%). ${ }^{36}$

\section{Infective Endocarditis}

Infective endocarditis during pregnancy is not very common, and estimated rates are 3 to 12 per 1,000 with prosthetic valves. ${ }^{37}$ The maternal and fetal mortality rates remain high at $33 \%$ and $29 \%$, respectively. Management principles should follow the guidelines for management in IE in nonpregnant situation. Care should be undertaken to use antibiotics safe in pregnancy such as penicillin, ampicillin, amoxicillin, erythromycin, and cephalosporins. Aminoglycosides and tetracyclines are harmful for the fetus at all times, and their use should be restricted as far as practical. Surgery becomes indispensable when the patient has refractory heart failure or cardiogenic shock, but fetal mortality remains high as previously alluded to.

\section{Arrhythmias}

Supraventricular arrhythmia and AF are the most common arrhythmias in pregnant women with cardiac disease. Ventricular tachyarrhythmias, though uncommon, predispose the patient to the risk of sudden cardiac death in presence of structural heart diseases. 
Preconception

- Thorough discussion about contraception use

- Detailed counseling about maternal, fetal, and neonatal risks

- For females considering pregnancy, discuss plan of pregnancy with explanation of all the risks

- Detailed clinical history, drug history, clinical examination

- Electrocardiogram, echocardiography (to look for ventricular function, prosthetic valve function, other concomitant diseases) as baseline

- Risk and benefits of anticoagulant therapy in females with mechanical valves

\section{Antepartum}

- Thorough history taking and clinical examination at 1st visit.

- Electrocardiogram, general blood investigation should be done

- Proper counseling regarding all complications, warning signs, lifestyle changes

- Follow-up visits should be individualized based on clinical status, patient specific characters, type of prosthetic valve, and type of anticoagulation

- Echocardiographic evaluation should be done in each trimester

- Mode of delivery-vaginal usually preferred (cesarean if patient taking warfarin presents with active labor)

\section{Labor}

- Time of delivery (induction of delivery when needed)

- Place of delivery (should be at the center where specialist care is available round the clock)

- Anesthesia and analgesia plan

- Anticoagulation regimen (when to stop VKAs, when to start and stop heparin )

- Females on oral anticoagulant, heparins, diuretic, and $\beta$-blockers can safely breastfeed their babies

Fig. 3 General principles of management in prosthetic vales with pregnancy. VKA, vitamin K antagonists.

For paroxysmal supraventricular tachycardia, adenosine is recommended for acute termination. $\beta$-Blocking agents, except (atenolol), are advised for prophylaxis. For atrial flutter and AF, the patient's hemodynamic status will guide the therapy. DC cardioversion is the therapy of choice in unstable patients whereas ibutilide or flecainide should be considered in stable patients. $\beta$-Blockers are again useful for rate control for long term.

For ventricular tachycardia (VT) with hemodynamic instability, DC cardioversion is required. In absence of adverse hemodynamic profile, intravenous sotalol or procainamide are preferred agents for rate control. Amiodarone should be reserved or refractory cases. $\beta$-Blocker again comes into picture for prophylaxis. An implantable cardioverterdefibrillator (ICD) should be implanted before pregnancy in high-risk clinical situations, but it can also be given for therapy-resistant VTs during pregnancy.

\section{Heart Failure}

Principles of management are same as those of out of pregnancy. However, the medical treatment needs to be tailored or adapted for pregnancy. ACE inhibitors, ARB, and direct renin inhibitors are avoided due to enhanced risk of fetal toxicity. ${ }^{38,39}$ Hydralazine and nitrate are safer alternatives to RAAS blockers. Dopamine and levosimendan are preferred inotropes. Diuretics should be used judiciously as they can be diminished placental flow. Spironolactone and eplerenone should be avoided. $\beta_{1}$ selective agents such as metoprolol should be preferred over atenolol. ${ }^{40}$

\section{Conclusion}

Pregnancy with prosthetic valves is a high-risk situation with increased maternal and fetal morbidity. Adequate risk stratification and continuous monitoring are the key to preempting complications. Tissue valves overall fare better with low thrombogenic risk and lack of dependency on anticoagulation but suffer the risk of structural degeneration of valve. Mechanical valves have excellent durability, but the need for seamless anticoagulation adds an additional burden of complications apart from the inherent thrombotic risk. However, use of lowdose VKAs and targeted substitution with parenteral heparin have brought down the maternal and fetal adverse events. However, despite improved outcomes, irrespective of valve used (tissue, mechanical-new or old, Ross procedure), there 
remains an enhanced risk vis-à-vis the cohort without any prosthetic valve. These patients are best managed in tertiary care center with a team expert comprising the obstetrician, cardiologist, hematologist, and neonatologist.

\section{Acknowledgment of Grant Support}

None.

\section{Conflicts of Interest}

None.

\section{References}

1 Robson SC, Hunter S, Boys RJ, Dunlop W. Serial study of factors influencing changes in cardiac output during human pregnancy. Am J Physiol 1989;256(4 Pt 2):H1060-H1065

2 Meah VL, Cockcroft JR, Backx K, Shave R, Stöhr EJ. Cardiac output and related haemodynamics during pregnancy: a series of meta-analyses. Heart 2016;102(7):518-526

3 Siu SC, Sermer M, Colman JM, et al; Cardiac Disease in Pregnancy (CARPREG) Investigators. Prospective multicenter study of pregnancy outcomes in women with heart disease. Circulation 2001;104(5):515-521

4 Drenthen W, Boersma E, Balci A, et al; ZAHARA Investigators. Predictors of pregnancy complications in women with congenital heart disease. Eur Heart J 2010;31(17):2124-2132

5 Khairy P, Ouyang DW, Fernandes SM, Lee-Parritz A, Economy KE, Landzberg MJ. Pregnancy outcomes in women with congenital heart disease. Circulation 2006;113(4):517-524

6 Thorne S, MacGregor A, Nelson-Piercy C. Risks of contraception and pregnancy in heart disease. Heart 2006;92(10):1520-1525

7 Regitz-Zagrosek V, Roos-Hesselink JW, Bauersachs J, et al; ESC Scientific Document Group. 2018 ESC guidelines for the management of cardiovascular diseases during pregnancy. Eur Heart J 2018;39(34):3165-3241

8 Regitz-Zagrosek V, Blomstrom Lundqvist C, Borghi C, et al; European Society of Gynecology (ESG); Association for European Paediatric Cardiology (AEPC); German Society for Gender Medicine (DGesGM); ESC Committee for Practice Guidelines. ESC guidelines on the management of cardiovascular diseases during pregnancy: the Task Force on the Management of Cardiovascular Diseases during Pregnancy of the European Society of Cardiology (ESC). Eur Heart J 2011;32(24):3147-3197

9 van Hagen IM, Roos-Hesselink JW, Ruys TP, et al; ROPAC Investigators and the EURObservational Research Programme (EORP) Team*. Pregnancy in women with a mechanical heart valve: data of the European Society of Cardiology Registry of Pregnancy and Cardiac Disease (ROPAC). Circulation 2015;132(2):132-142

10 Lawley CM, Lain SJ, Algert CS, Ford JB, Figtree GA, Roberts CL. Prosthetic heart valves in pregnancy, outcomes for women and their babies: a systematic review and meta-analysis. BJOG 2015;122(11):1446-1455

11 D'Souza R, Ostro J, Shah PS, et al. Anticoagulation for pregnant women with mechanical heart valves: a systematic review and meta-analysis. Eur Heart J 2017;38(19):1509-1516

12 Elkayam U, Bitar F. Valvular heart disease and pregnancy: part II: prosthetic valves. J Am Coll Cardiol 2005;46(3):403-410

13 North RA, Sadler L, Stewart AW, McCowan LM, Kerr AR, White HD. Long-term survival and valve-related complications in young women with cardiac valve replacements. Circulation 1999;99(20):2669-2676

14 Egbe AC, Pislaru SV, Pellikka PA, et al. Bioprosthetic valve thrombosis versus structural failure: clinical and echocardiographic predictors. J Am Coll Cardiol 2015;66(21):2285-2294
15 Jamieson WR, Rosado LJ, Munro AI, et al. Carpentier-Edwards standard porcine bioprosthesis: primary tissue failure (structural valve deterioration) by age groups. Ann Thorac Surg 1988;46(2):155-162

16 Flameng W, Rega F, Vercalsteren M, Herijgers P, Meuris B. Antimineralization treatment and patient-prosthesis mismatch are major determinants of the onset and incidence of structural valve degeneration in bioprosthetic heart valves. J Thorac Cardiovasc Surg 2014;147(4):1219-1224

17 Avila WS, Rossi EG, Grinberg M, Ramires JA. Influence of pregnancy after bioprosthetic valve replacement in young women: a prospective five-year study. J Heart Valve Dis 2002;11(6):864-869

18 Grunkemeier GL, Li H-H, Naftel DC, Starr A, Rahimtoola SH. Long-term performance of heart valve prostheses. Curr Probl Cardiol 2000;25(2):73-154

19 Vause S, Clarke B, Tower CL, Hay C, Knight M; (on behalf of UKOSS). Pregnancy outcomes in women with mechanical prosthetic heart valves: a prospective descriptive population based study using the United Kingdom Obstetric Surveillance System (UKOSS) data collection system. BJOG 2017;124(9):1411-1419

20 Chan WS, Anand S, Ginsberg JS. Anticoagulation of pregnant women with mechanical heart valves: a systematic review of the literature. Arch Intern Med 2000;160(2):191-196

21 Hassouna A, Allam H. Anticoagulation of pregnant women with mechanical heart valve prosthesis: a systematic review of the literature (2000-2009). J Coagul Disord 2010;2:81-88

22 Abildgaard U, Sandset PM, Hammerstrøm J, Gjestvang FT, Tveit A. Management of pregnant women with mechanical heart valve prosthesis: thromboprophylaxis with low molecular weight heparin. Thromb Res 2009;124(3):262-267

$23 \mathrm{Xu} Z$, Fan J, Luo X, et al. Anticoagulation regimens during pregnancy in patients with mechanical heart valves: a systematic review and meta-analysis. Can J Cardiol 2016;32(10):1248. e1-1248.e9

24 Hung L, Rahimtoola SH. Pregnancy and heart valves. Circulation 2003;107:1240-1246

25 Shaul WL, Emery H, Hall JG. Chondrodysplasia punctata and maternal warfarin use during pregnancy. Am J Dis Child 1975;129(3):360-362

26 Bremme KA. Haemostatic changes in pregnancy. Best Pract Res Clin Haematol 2003;16(2):153-168

27 Vitale N, De Feo M, De Santo LS, Pollice A, Tedesco N, Cotrufo M. Dose-dependent fetal complications of warfarin in pregnant women with mechanical heart valves. J Am Coll Cardiol 1999;33(6):1637-1641

28 Cotrufo M, De Feo M, De Santo LS, et al. Risk of warfarin during pregnancy with mechanical valve prostheses. Obstet Gynecol 2002;99(1):35-40

29 Baumgartner H, Falk V, Bax JJ, et al; ESC Scientific Document Group. 2017 ESC/EACTS guidelines for the management of valvular heart disease. Eur Heart J 2017;38(36):2739-2791

30 Nishimura RA, Otto CM, Bonow RO, et al; ACC/AHA Task Force Members. 2014 AHA/ACC guideline for the management of patients with valvular heart disease: a report of the American College of Cardiology/American Heart Association Task Force on Practice Guidelines. Circulation 2014;129(23):e521-e643

31 Quinn J, Von Klemperer K, Brooks R, Peebles D, Walker F, Cohen $\mathrm{H}$. Use of high intensity adjusted dose low molecular weight heparin in women with mechanical heart valves during pregnancy: a single-center experience. Haematologica 2009;94(11):1608-1612

32 Basude S, Hein C, Curtis SL, Clark A, Trinder J. Low-molecular-weight heparin or warfarin for anticoagulation in pregnant women with mechanical heart valves: what are the risks? A retrospective observational study. BJOG 2012;119(8):1008-1013, discussion 1012-1013 
33 Bhagra CJ, D'Souza R, Silversides CK. Valvular heart disease and pregnancy part II: management of prosthetic valves. Heart 2017;103(3):244-252

34 Little SH, Massel DR. Antiplatelet and anticoagulation for patients with prosthetic heart valves. Cochrane Database Syst Rev 2003;(4):CD003464

35 Özkan M, Çakal B, Karakoyun S, et al. Thrombolytic therapy for the treatment of prosthetic heart valve thrombosis in pregnancy with low-dose, slow infusion of tissue-type plasminogen activator. Circulation 2013;128(5):532-540

36 Weiss BM, von Segesser LK, Alon E, Seifert B, Turina MI. Outcome of cardiovascular surgery and pregnancy: a systematic review of the period 1984-1996. Am J Obstet Gynecol 1998;179(6 Pt 1):1643-1653
37 Habib G, Lancellotti P, Antunes MJ, et al; ESC Scientific Document Group. 2015 ESC guidelines for the management of infective endocarditis. Eur Heart J 2015;36(44):3075-3128

38 Schaefer C. Angiotensin II-receptor-antagonists: further evidence of fetotoxicity but not teratogenicity. Birth Defects Res A Clin Mol Teratol 2003;67(8):591-594

39 Cooper WO, Hernandez-Diaz S, Arbogast PG, et al. Major congenital malformations after first-trimester exposure to ACE inhibitors. N Engl J Med 2006;354(23):2443-2451

40 Lydakis C, Lip GY, Beevers M, Beevers DG. Atenolol and fetal growth in pregnancies complicated by hypertension. Am J Hypertens 1999;12(6):541-547 